\title{
Colitis ulcerosa e infección por citomegalovirus
}

\author{
I. TÁRRAGA RODRÍGUEZ, P. FERRERAS FERNÁNDEZ, \\ M. VICENTE GUTIÉRREZ, J. J. DE ARRIBA, M. L. GARCÍA MOURIÑO \\ Servicios de Medicina Interna, Digestivo y Anatomía Patológica. Hospital General. \\ Albacete
}

\author{
COLITIS ULCEROUS AND CITOMEGALOVIRUS INFECTION
}

\begin{abstract}
RESUMEN
La asociación entre colitis ulcerosa de debut e infección por citomegalovirus ha sido descrita en la literatura pero en contadas ocasiones (1), aunque se observa un aumento de la prevalencía en los ultimos años. Presentamos un caso clínico con esta asociación y realizamos una revisión de la literatura médica. No se conocen con claridad los factores implicados ní tampoco el orden causal de esta asociación, precisando estudios más completos para intentar alcanzar soluciones definitivas.
\end{abstract}

PALABRAS CLAVE: Colitis ulcerosa. Infección por citomegalovirus.

\begin{abstract}
Colitis ulcerous and citomegalovirus infection association have been reported in medical literature in sometimes, althrougth this prevalence have lately increased. We report a case record of this association and do a rewiew of this subjet.It is not clear what factors are involved in this association, being necessary hore studies to know them.
\end{abstract}

KEY WORDS: Colitis ulcerous. Citomegalovirus infection.

Tárraga Rodríguez I, Ferreras Fernández P, Vicente Gutiérrez M, de Arriba JJ, García Mouriño ML. Colitis ulcerosa e infección por citomegalovirus. An Med Interna (Madrid) 2003; 20: 85-87.

\section{INTRODUCCIÓN}

La asociación entre enfermedad inflamatoria e infección por citomegalovirus ha sido descrita ya en la literatura médica, en una revisión de la literatura médica se han descrito al menos 35 casos (desde 1980 hasta la fecha) que asocian colitis ulcerosa e infección por citomegalovirus, siendo en la mayor parte de los casos infecciones víricas en el contexto de pacientes inmunodeprimidos por el tratamiento de base para la colitis ulcerosa. Son muchos menos los casos de asociación entre colitis ulcerosa de debut e infección por CMV y por tanto sin ningún tipo de inmunosupresión farmacológica.

A continuación se presenta un nuevo caso de asociación entre colitis ulcerosa de debut e infección por citomegalovirus.

\section{CASO APORTADO}

Varón de 75 años sin alergias medicamentosas conocidas, tractorista jubilado, con antecedentes de brucelosis en la juventud, exfumador de 5 cigarrillos desde hace 2 años y bebedor de aproximadamente 25 gramos de etanol al día. Unos 15-20 días antes del ingreso comienza con deposiciones verdosas sin moco sangre o pus, con presencia de dolor abdominal tipo cólico y sensación vespertina de escalofrios. A la exploración física tensión arterial de $120 / 80 \mathrm{~mm} \mathrm{Hg}$, temperatura de $37,4^{\circ} \mathrm{C}$, aceptable estado general, sequedad de piel y mucosas, normocoloreado. No ingurgitación yugular no bocio no soplo carotídeo no adenopatías laterocervicales. Auscultación cardiaca rítmica sín soplo a 85 1/m. Auscultación pulmonar: mvc con algún crepitante en ambas bases no taquipneico. Abdomen distendido con timpanismo a la percusión, con dolor a la palpación profunda en todo el abdomen pero sin signos de peritonismo y con ruidos intestinales presentes aunque algo disminuidos, en tacto rectal no se objetivan heces en ampolla. Puñopercusión renal negativa bilateral. Extremidades sin edemas, no signos de isquemia ni de trombosis venosa profunda. En cuanto a las exploraciones complementarias en el hemograma presenta 7.959 leucocitos $/ \mathrm{mm}$ con $58 \%$ de neutrófilos, $20,2 \%$ de linfocitos, $15,4 \%$ de monocitos y $0,5 \%$ de eosinofilos. Destaca en la bioquímica una GOT de $76 \mathrm{U} / \mathrm{L}$, GPT $65 \mathrm{U} / \mathrm{L}, \mathrm{GGT} 79 \mathrm{U} / \mathrm{L}$ y VSG de $28 \mathrm{~mm} 1^{\text {a }}$ hora, resto normal. Sedimento de orina sin hallazgos a referir y coagulacion normal. En cuanto a los cultivos tanto hemocultivos, urocultivos y coprocultivos son negativos. Toxina de Clostridium

Trabajo aceptado: 20 de noviembre de 2001

Correspondencia: Ignacio Tárraga Rodríguez. C/ Cruz Norte, 11, 4-G. 2001 Albacete. e-mail: nachotarraga@ono.com 
difficile negativa. Serologia de atipicas negativa. Serología de VIH negativa. Serología CMV IgG CMV > 10 U/L con IGM CMV positiva. Poblaciones celulares normales. ANA positivo 1/40. Alfafetoproteína, PSA, CEA, CA19,9 y CA125 normales. Mantoux negativo. Radiografía de tórax compatible con la normalidad. Radiografía de abdomen (Fig. 1) con dilatacion intestinal que afecta al intestino delgado y al colon con distensión del colon transverso en mayor intensidad. En ecografía abdominal aparece un hígado homogéneo no aumentado de tamaño, con porta de $1,2 \mathrm{~cm}$ en el límite alto de la normalidad, con vesícula y vía biliar intra-extrahepática sin alteraciones, riñones con quistes corticales y páncreas no valorable por gas. En enema opaco aparecen imágenes de engrosamiento de la pared del colon descendente con formaciones ulcerosas compatible con colitis ulcerosa de dicha porción del colon. En TAC abdómino-pélvico se observan 3 imágenes puntiformes hipodensas localizadas en el lóbulo hepático derecho en relación con pequeños quistes simples, no apreciándose imagen compatible con absceso intraabdominal y llamando la atención un engrosamiento de la pared intestinal con separación de asas compatible con edema de pared. En las colonoscopias efectuadas (Fig. 2) se observa desde el ano hasta mitad de transverso la mucosa afectada de forma continua con eritema, edema, pérdida de brillo y úlceras de tamaños variables que dan un aspecto empedrado a esta mucosa con el diagnóstico de colitis inespecífica. En resultados de la biopsia efectuada con la colonoscopia se concluye con la existencia de colitis inespecífica con ulceración sugestivo de lesión viral, encontrandose imágenes características de inclusiones por citomegalovirus en las células endoteliales. En cuanto a la evolución a su llegada a planta se inicia tratamiento con fluidoterapia intravenosa y tratamiento antibiótico con ciprofloxacino y metronidazol persistiendo las

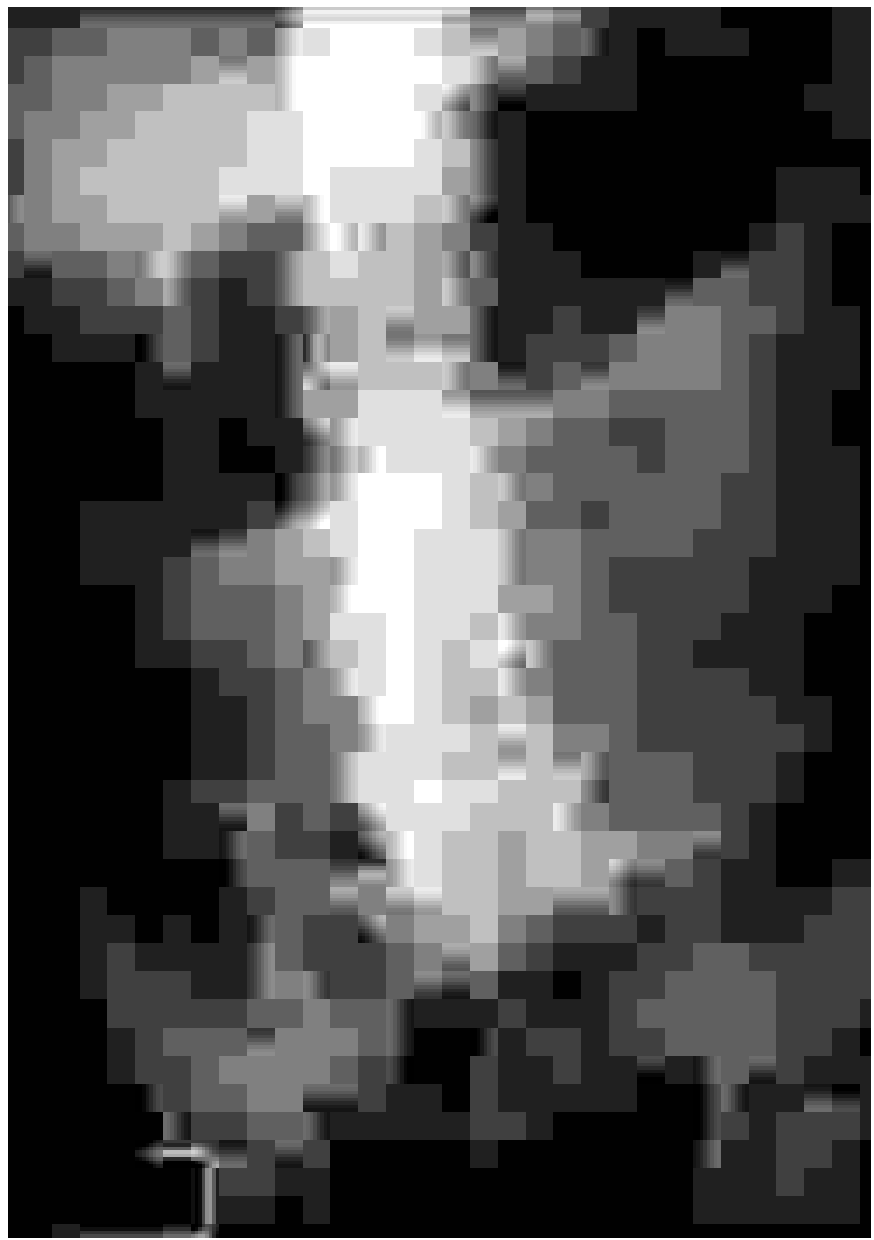

Fig. 1. Distensión del colon transverso en Rx de abdomen.

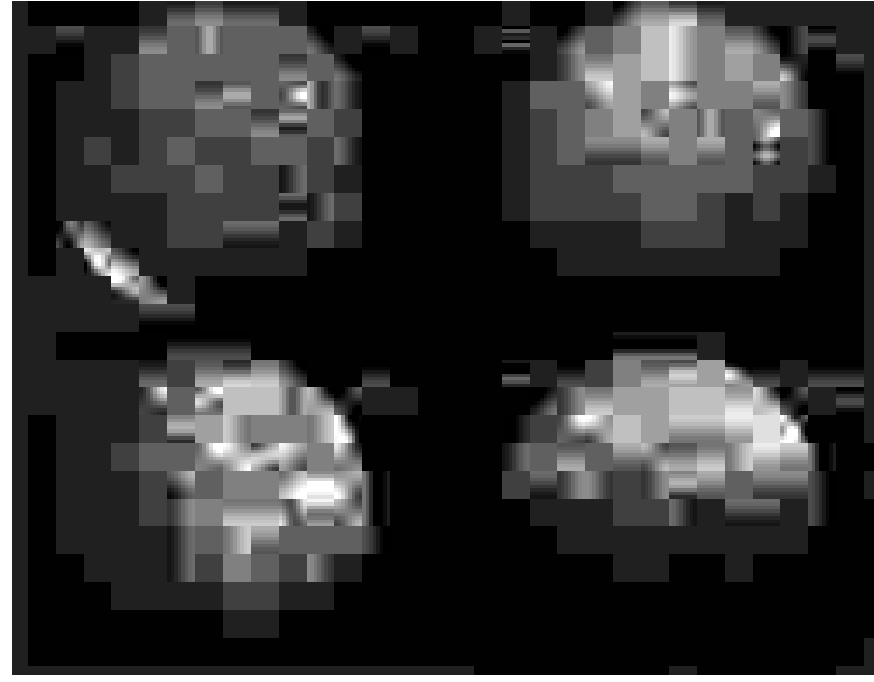

Fig. 2. Imagen endoscópica del colón apreciándose úlceras y mucosa con aspecto de empedrado en el colon descendente y sigma respetando el recto.

deposiciones diarreicas y los picos febriles. Se inicia nutricion enteral y parenteral por desnutricion importante, iniciándose tratamiento con imipemen por picos de fiebre. Recibidos los resultados de la biopsia se inició tratamiento con ganciclovir y a los 10 dias por ausencia de mejoria se añaden corticoides intravenosos observándose en principio mejoría clínica y desaparición de la fiebre, no obstante pasados unos dias más y aunque persiste apirético aumenta la distensión abdominal llegando a la perforación que lleva a tratamiento quirúrgico con resección de sigma y colon descendente, realizando colostomia de descarga de ascendente a flanco derecho con buena evolución posterior. En el informe anatomopatológico de la pieza de colon transverso se concluye con la existencia de colitis ulcerosa.

\section{DISCUSIÓN}

En la revisión de la literatura médica desde 1980 hasta la fecha se han encontrado al menos 35 casos de asociación entre colitis ulcerosa e infección por citomegalovirus, pero ser capaces de explicar cual es el factor causal inicial o los factores añadidos que pudieran actuar es una cuestion que a la luz de los conocimientos médicos actuales permanece todavía oscura (2). Lo que se desprende de las ultimas publicaciones respecto de esta asociación es el aumento de la prevalencia en los ultimos años, aunque nos podemos plantear la pregunta de sí es realmente más prevalente por que realmente es así o bien por el contrario es más prevalente por que ahora se busca más (3). En aquellos enfermos con diagnóstico previo de colitis ulcerosa y tratamiento con corticoides u otros inmunosupresores parece clara la asociación apareciendo la infección por CMV en el contexto de la inmunodepresión (4). No parece tan clara en aquellos enfermos como el que nos ocupa y en los otros restantes encontrados en la literatura médica, en los que no hay previamente ningún dato de inmunosupresión ni médica ni congénita.

En estos casos algunos autores abogan por la existencia de una enfermedad clínicamente silente o subclínica activa- 
da por un proceso infeccioso como el CMV que despliega el proceso inflamatorio en toda su intensidad (5), aunque realmente pudieran intervenir otros procesos no conocidos hasta la fecha infecciosos, inmunológicos o de otra índole. Por otra parte y para complicar más la situación está por definir si se trata de una infección activa o de una enfermedad por citomegalovirus y cuales serían los métodos diagnósticos a utilizar desde el punto de vista clínico (6). Existen autores que abogan una vez identificada la asociación entre colitis ulcerosa e infección por CMV por la supresión del tratamiento inmunosupresor con corticoides y con la administración de ganciclovir (7), otros autores por el contrario se muestran reticentes en la supresión del tratamiento corticoi- deo puesto que se ha demostrado que en aquellos casos en los que se ha suprimido este la enfermedad inflamatoria de base ha presentado mayor número de brotes e incluso con mayor virulencia (5). Por otra parte no está claro el tratamiento con ganciclovir evite la presentación de nuevos brotes de colitis ulcerosa aunque sí que se ha demostrado que en aquellos casos en los que se ha asociado la duración del brote agudo ha sido menor (4). Otro aspecto ha considerar sería la presencia de resistencias cada vez más frecuentes al tratamiento con ganciclovir por presencia de determinadas mutaciones a nivel del gen de la DNA polimersa con la consiguiente sustitución por otros fármacos del tipo del foscarnet o cidofovir (8).

\section{Bibliografía}

1. Klauber E, Laurence E. Cytomegalovirus colitis in the immunocopetent Host: An Overwien. Scand J Infect Dis 1998: 30; 599-64.

2. Maté del Tio M, Peña Sánchez de Rivera JM, Larrauri Martinez J, Garcés Jiménez MC. Asociación de colitis por citomegalovirus y primer brote de colitis ulcerosa en un paciente inmunocompetente. Gastroenterol Hepatol $1996 ; 19 ; 206$

3. Alcala MJ, Casellas F, Pallarés J. Infección por citomegalovirus en pacientes con colitis ulcerosa tratados con colectomía. Med Clin (Barc) 2000; 114: 201-4

4. Pérez JL. Infección por citomegalovirus y enfermedad inflamatoria intestinal. Med Clin (Barc) 2000; 114: 217-8.

5. De La Serna Higuera C, Urman Fernández JM, Cano Ruiz A. Tratamiento antiviral en pacientes con brote agudo de colitis ulcerosa colónica por citomegalovirus. Gastroenterol Hepatol 1998; 21: 26.

6. Valle Yague, Cour I, Alvarez R, Fernández C, Picazo J. Citomegalovirus: estudio comparativo de técnicas de diagnóstico. Enferm Infecc Microbiol Clin 1998; 16: 163-8.

7. Vega R, Bertrán X, Menacho M, Doménech E, Moreno De Vega V. Cytomegalovirus Infection in Patients With Inflammatory Bowel disease. Am J Gastroenterol 1999; 94: 1053-6.

8. Laurance W. Treatment of drug-resistant cytomegalovirus (CMV) disease. Infect Med 2000; 17 (11): 737-44. 